\title{
Pregnancy Termination in Matlab, Bangladesh: Maternal Mortality Risks Associated with Menstrual Regulation and Abortion
}

\author{
By Mizanur \\ Rahman, Julie \\ DaVanzo and \\ Abdur Razzaque \\ Mizanur Rahman \\ is senior research \\ associate, Carolina \\ Population Center, \\ University of North \\ Carolina, Chapel \\ Hill, USA. Julie \\ DaVanzo is senior \\ economist, RAND, \\ Santa Monica, CA, \\ USA. Abdur Raz- \\ zaque is scientist and \\ manager, Health \\ and Demographic \\ Surveillance System, \\ International Centre \\ for Diarrhoeal \\ Disease Research, \\ Bangladesh, Dhaka.
}

\begin{abstract}
CONTEXT: In Bangladesh, both menstrual regulation (MR), which is thought to be a relatively safe method, and abortion, which in this setting is often performed using unsafe methods, are used to terminate pregnancies (known or suspected). However, little is known about changes over time in the use of these methods or their relative mortality risks.
\end{abstract}

METHODS: Data from the Demographic Surveillance System in Matlab, Bangladesh, on 110,152 pregnancy outcomes between 1989 and 2008 were used to assess changes in mortality risks associated with MR (and a small number of dilation and curettage procedures), abortion and live birth. Tabulation and logistic regression analyses were used to compare outcomes in two areas of Matlab-the comparison area, which receives standard government health and family planning services, and the Maternal and Child Health-Family Planning (MCH-FP) area, which receives enhanced health and family planning services.

RESULTS: In Matlab as a whole, the proportion of pregnancies ending in MR increased from 1.9\% in 1989-1999 to $4.2 \%$ in $2000-2008$, while the proportion ending in abortion decreased from $1.6 \%$ to $1.1 \%$. The odds of mortality from MR were 4.1 times those from live birth in 1989-1999, but were no longer elevated in 2000-2008. The odds of mortality from abortion were 12.0 and 4.9 times those of live birth in 1989-1999 and 2000-2008, respectively. Reduction in mortality risk was greater in the MCH-FP area than the comparison area (90\% vs. $75 \%$ ).

CONCLUSION: MR is no longer associated with higher mortality risk than live birth in Bangladesh, but abortion is. International Perspectives on Sexual and Reproductive Health, 2014, 40(3):108-118, doi: 10.1363/4010814

Although maternal mortality rates in developing countries have declined in recent years, they remain unacceptably high. ${ }^{1}$ Achieving Millennium Development Goal 5-the reduction of maternal mortality by three-quarters between 1990 and 2015-remains a challenge. In Bangladesh, the maternal mortality ratio (MMR) declined by $66 \%$ from 1990 to 2010, to an estimated 194 maternal deaths per 100,000 live births. ${ }^{2}$ Although this level is high compared with that in developed countries, the decline is remarkable considering Bangladesh's relatively unfavorable socioeconomic conditions, poorly managed health infrastructure and low rates of institutional deliveries..$^{1-3}$ The reduction in maternal mortality may be due to fertility decline, to changes in health care-seeking behavior ${ }^{3}$ and to the availability of menstrual regulation (MR), a form of uterine evacuation that is thought to be a relatively safe method of terminating pregnancies (or suspected pregnancies). Studies suggest that MR and abortion have been widespread in Bangladesh, ${ }^{4,5}$ and that the incidence of the former has been increasing. ${ }^{6,7}$ In this study, we used longitudinal data from Matlab to examine the case-fatality rates associated with $\mathrm{MR},{ }^{*}$ abortion and live birth. We also assessed whether the case-fatality rates of MR and abortion differ, and whether they have declined recently, as maternal mortality has.

*As we explain in more detail later, our MR sample included a small number of women who had undergone dilation and curettage.
Pregnancy termination is legal in Bangladesh when practiced to save a woman's life and, under the guise of $\mathrm{MR}$, in the early stages of pregnancy. MR is permitted to bring on delayed menses within 10 weeks of a woman's last menstrual period; it is done using manual or electric vacuum aspiration before pregnancy is clinically confirmed. Although we do not know of any data on how often the women who undergo MR are pregnant, we (and others) strongly suspect that most such women presume, probably correctly, that they are pregnant. MR is available from trained female providers-family welfare visitors at public-sector facilities in rural areas, and paramedics at nongovernmental organizations and private health centers in urban and rural areas. In addition, male and female physicians are trained in MR and in some cases provide the service. Physicians are permitted by law to perform MR up to 10 weeks after a woman's last menstrual period, while family welfare visitors and paramedics may do so up to eight weeks after the last menstrual period. ${ }^{4} \mathrm{~A}$ husband's consent is not legally required prior to the procedure, but many providers at public-sector facilities ask for it. MR is supposed to be free of charge from public-sector providers, but for various reasons clients typically pay a considerable amount of money, even in the public sector, for medications, laboratory tests and other out-of-pocket costs. Providers are required to keep records of MRs, which may raise clients' concerns about confidentiality. 
Abortion remains a very sensitive topic in Bangladesh; many of the restrictions on MR, particularly its availability only before pregnancy is clinically confirmed, are meant to reinforce the perception that the procedure is something other than abortion. MR is not considered abortion by most women, who sometimes call the procedure "wash." Dilation and curettage ( $D \& C$ ) is another procedure for pregnancy termination available from nurses or physicians at public and private health facilities; however, as our data show, its incidence is very low in our study area.

Terminating a pregnancy in a nonmedical setting or after pregnancy is clinically confirmed is prohibited in Bangladesh, except to save a woman's life. Nevertheless, research suggests that clandestine and unsafe pregnancy terminations have been common. ${ }^{4,8}$ An abortion can be obtained from traditional practitioners, usually older women who perform the procedure by inserting herbal roots or other solid objects into the uterus. In rural areas (such as the one studied here) and urban slums, traditional practitioners typically are more available than formally trained providers are. Although clandestine abortions are cheaper than MR, they are less safe and are a leading cause of maternal mortality and short- and long-term maternal health complications.

While MR is technically not regarded as pregnancy termination in Bangladesh, most studies in the reproductive health literature treat it as such. For example, articles on abortion, ${ }^{6-10}$ maternal morbidity ${ }^{11}$ and maternal mortality ${ }^{2,3,12-15}$ included MR when they referred to abortion. Because we compare mortality risks between MR and abortion, as well as to be consistent with the literature, we treat MR as a method of pregnancy termination, and use the term "pregnancy termination" or "termination" to describe both abortion and MR (and D\&C).

\section{Maternal Mortality in Bangladesh}

National data on maternal mortality in Bangladesh have been scarce, although some regional data from crosssectional surveys and high-quality longitudinal surveillance have been available. During the 1980s, the maternal mortality ratio was estimated to be between 550 and 623 deaths per 100,000 live births in three geographically dispersed districts. ${ }^{16-18}$ In Matlab, where high-quality longitudinal data are available, the maternal mortality ratio was estimated as 443, 313 and 170 per 100,000 in the 1980s, 1990s and early 2000s, respectively. ${ }^{13}$ Two large national maternal mortality surveys yielded estimates of 322 per 100,000 in 1998-2001 and 194 per 100,000 in 20082011. 2,3 These findings suggest that maternal mortality has declined remarkably since the 1980s and that the maternal mortality ratio has fallen below 200 per 100,000 live births.* They further indicate that Bangladesh is on track to meet Millennium Development Goal 5; the decline in maternal mortality is consistent with the country's dramatic reductions in fertility and childhood mortality and with its rapid social development.

The two national surveys found that the proportion of maternal mortality attributable to abortion was very low5\% in 1998-2001 and 1\% in 2008-2011.2,3 In Matlab, surveillance data on abortion-related maternal mortality, which are likely to be more reliable than survey data on these issues, also show a decline-from 89 abortion-related deaths per 100,000 pregnancies in 1976-1985 and 72 per 100,000 in 1986-1995 to 31 per 100,000 in 1996-2005but the proportions of maternal deaths attributable to abortion (20\% in 1976-1995, 13\% in 1996-2005) are considerably higher than those estimated from survey data. ${ }^{14}$ The discrepancy is probably due to the difficulty of identifying abortion cases in surveys, especially for women who die early in pregnancy. Family members tend not to report information on abortion in surveys, and the likelihood of their disclosing abortion cases is probably lower for women who have died.

\section{Study Area}

Matlab, a rural subdistrict of Bangladesh, is well known for its Demographic Surveillance System (DSS), as well for the Maternal Child Health-Family Planning (MCH-FP) project, which operates in half of the DSS area to provide intensive, high-quality reproductive health, family planning, and maternal and child health services. ${ }^{19-21}$ The other half, known as the comparison area, is typical of much of Bangladesh in contraceptive use, ${ }^{22}$ fertility and childhood mortality, ${ }^{23}$ and maternal mortality. ${ }^{2}$ The MCH-FP area has lower rates of fertility, ${ }^{24}$ pregnancy termination ${ }^{9}$ and maternal mortality, ${ }^{12,23}$ provides greater coverage of antenatal care and offers better access to basic and emergency obstetric care ${ }^{13,24}$ than the comparison area does.

Most women in Matlab deliver at home with the help of a traditional birth attendant, although institutional deliveries, which were rare as recently as the early 1990s, have increased sharply in the MCH-FP area in recent years. ${ }^{14}$ Both areas of Matlab have access to Chandpur government district hospital and to some private clinics that provide emergency and intensive-care services, including caesarean delivery and blood transfusion. However, about half of the villages in both areas are relatively remote, and traveling to Chandpur is difficult.

The MCH-FP project-a series of carefully designed reproductive health interventions that may directly and indirectly affect maternal health and mortality-was implemented in Matlab in 1977. The project provided MR services from 1978 to 1983, but not since then. Between 1978 and 2001, female community health workers provided injectable contraceptives, the pill, condoms and family planning counseling during household visits every two weeks (1978-1995) or monthly (1996-2001). Tetanus immuni-

\footnotetext{
*Global models estimate a higher maternal mortality ratio for Bangladesh-about 340 per 100,000 in 2008 (sources: reference 1 and Hogan MC et al., Maternal mortality for 181 countries, 1980-2008: a systematic analysis of progress towards Millennium Development Goal 5, Lancet, 2010,375(9726):1609-1623). However, these models may not fit the Bangladesh situation, primarily because the country has experienced a rapid demographic transition and improvements in public health. The practice of MR also may contribute to the maternal mortality ratio's being lower in Bangladesh than is predicted by these models.
} 
zation was introduced in 1979, and coverage has been universal since 1990. In 1982, a basic safe-motherhood intervention, which included antenatal screening performed by female community health workers using a simple screening tool, was initiated. Additional safe-motherhood interventions were introduced beginning in 1987, when four health centers were established in the area; four trained midwives, on call 24 hours a day, were posted in two of the four health centers to attend at-home deliveries. Midwives encouraged pregnant women with complications to seek care from the Matlab Heath Center, where emergency care (but not caesarean section or blood transfusion) was available; women with serious complications were transported to the district hospital in Chandpur. In 1990, midwives were posted in the other two health centers to provide the above-mentioned services. Since 1983, pregnant women in the MCH-FP area have received from community health workers information about antenatal care, as well as a card depicting common pregnancy complications; women are referred to midwives for counseling and for antenatal and delivery services. From 1996 to 2002, 58\% of pregnant women received at least one antenatal check-up from the health centers; of those who did, 90\% had a check-up during their third trimester. ${ }^{24}$ Between 1996 and 2001, the project replaced home-based maternity care by midwives with facility-based obstetric and delivery care at the four health centers; since 2001, health and family planning services have also been provided at these centers, and postabortion care is available as well. The MCH-FP project has made systematic efforts to increase institutional deliveries at the four health centers. ${ }^{13,14,25,26}$

As mentioned, the comparison area is served by the standard government program, and residents do not have access to the range of maternal health services available in the MCH-FP area. For example, in 2005, only 14\% of deliveries in the comparison area occurred in facilities, compared with $53 \%$ of those in the MCH-FP area. ${ }^{14}$ Access to MR and abortion is similar in the two areas; the former is provided by government providers and the latter by unskilled providers. However, because women in the $\mathrm{MCH}$ FP area have greater access to reproductive health information and counseling than do their peers in the comparison area, they are more likely to opt for safer termination methods, such as MR, than are women in the comparison area.

\section{Hypotheses}

We tested several hypotheses about the incidence of MR and abortion, their case-fatality rates, changes in these measures over time, and the relationship between the MCH-FP program and termination incidence and case fatality. A companion article investigates correlates of the two types of termination. ${ }^{6}$ As mentioned, women in the $\mathrm{MCH}$ FP area have greater access to quality reproductive health information, counseling, family planning services and postabortion care services than those in the comparison area; they are less likely to have unintended pregnancies and are more likely to be aware of appropriate health care options and to seek care. ${ }^{14}$ Moreover, the pace of health care improvement has been greater in the MCH-FP area.

Therefore, our first hypothesis is that relative to the comparison area, the MCH-FP area has had lower rates of pregnancy termination (overall and for MR and abortion separately); a higher proportion of terminations done by MR, rather than by abortion; lower case fatality for each type of pregnancy termination; and a greater reduction over time in case fatality (overall and for MR and abortion separately).

Each pregnancy puts a woman's life and health at risk. In Bangladesh, maternal mortality is lowest for women who have live births and highest for women with stillbirths; mortality rates among women who have miscarriages or terminate their pregnancies fall in between. ${ }^{12}$ However, the mortality risks associated with MR and abortion may differ considerably. Worldwide, the estimated fatality rate associated with unsafe abortion was about 220 per 100,000 procedures in 2008-around 350 times that of legal abortion in the United States. ${ }^{27}$ Moreover, the mortality risk associated with pregnancy terminations performed by trained practitioners in hygienic institutional settings should be lower than that associated with a live birth, because a full-term pregnancy ending in childbirth may pose greater health risks than an early-term pregnancy terminated under safe conditions. In the United States, the mortality rate among women who had legal abortions was less than one per 100,000 in the 1980s and 1990s, ${ }^{28,29}$ compared with 12 maternal deaths per 100,000 live births. ${ }^{1}$ In Bangladesh, however, MR is done in settings (health facilities or providers' homes) that, especially in rural areas, may not be as safe as sometimes presumed. In 1996, an estimated 25\% of women hospitalized for complications of pregnancy termination had undergone MR. ${ }^{5}$ Moreover, although more than $75 \%$ of pregnancy terminations were performed by MR, terminations accounted for $48 \%$ of obstetric complications in Jessore, Bangladesh, in 2008, ${ }^{11}$ suggesting that $\mathrm{MR}$ is associated with high levels of complications. For this reason, the mortality advantage of MR over live birth may not be as high in Matlab as in developed countries, and may not exist at all.

However, MR may be safer than abortion. Singh et al. estimated that for every 1,000 Bangladeshi women aged 15-44, about 6.5 were treated for complications of abortion and 2.2 were treated for complications of MR in 2010. ${ }^{4}$ Thus, our second hypothesis is that the maternal mortality risk associated with MR will be lower than that for abortion.

As noted, maternal mortality has declined in recent years in Bangladesh, purportedly because of increases in access to health programs, in women's education levels, in health awareness (and associated behavior) and in economic conditions, all of which allow women to procure health services, including in life-threatening circumstances. ${ }^{3}$ For example, among women with maternal complications, the proportion seeking treatment from providers increased from 53\% in 1998-2001 to 68\% in 2008- 
2010, and the proportion seeking treatment at facilities nearly doubled, from $15 \%$ to $29 \%{ }^{3}$

Moreover, advances in infrastructure, technology and medicine have facilitated access to care among women with complications of pregnancy termination. Road networks have expanded; access to transportation has improved; use of cell phones has become widespread, allowing women to obtain information and locate and mobilize emergency services in a timely fashion; and the availability of antibiotics has improved markedly through provision by less-skilled health-care providers. Several trends in careseeking, such as women using safer termination methods at earlier stages of pregnancy (when the risk of complications is relatively low), also may be contributing to declines in case-fatality rates from pregnancy termination.

Thus, we examined the following hypotheses: The mortality risks associated with MR and abortion have each declined; the decline in mortality risk from pregnancy termination is due both to reductions in the case-fatality rates and to changes in the relative shares of MR and abortion; pregnancies are being terminated at earlier stages than in the past; and women are using safer abortion methods than they did previously.

\section{DATA AND METHODS}

The Matlab DSS contains longitudinal records of pregnancy outcomes and deaths of household members. During their regular visits to each household-every two weeks in 1966-1999, monthly in 2000-2006 and bimonthly since 2007-female community health workers record women's pregnancy status and any pregnancy outcomes that occurred since the previous visit. Pregnancy outcomes are classified as live births, stillbirths, spontaneous miscarriages or induced miscarriages. The last category encompasses what we refer to as pregnancy terminations.

The coverage of pregnancy outcomes in the DSS appears to be quite complete; because female community health workers make regular household visits and are well known to and trusted by the community, women report the outcomes of almost all pregnancies, including those that are terminated. However, some underreporting is possible because of the stigma associated with abortion. 8,19 Moreover, pregnancies that women recognize after a community health worker visits and terminate before the next visit would not be recorded as terminations unless reported as such by the women; these pregnancies would be of quite short duration.*

Since 1989, the DSS has collected information on the method of pregnancy termination reported by respondents, although for unknown reasons this distinction was not made in 2001. Excluding that year, a total of 5,211 pregnancy terminations were recorded by the DSS in 1989-2008. Of these, 3,383 (65\%) were by MR and 106 ( $2 \%$ ) by D\&C; in this study, we refer to pregnancy terminations done using either method as MRs, because D\&C (which is provided by trained nurses or physicians) should be a relatively safe method of pregnancy termination. The other 1,722 terminations during the study period (33\%)what we call abortions-were done using other methods, which the DSS records in layman's terms. The two main methods of abortion recorded in the survey were internal manipulation of the female genitalia (821 pregnancies) and drug application (594 pregnancies); other reported methods were manipulation of the abdomen (80), injections (72) and drug ingestion (47). Abortion method was not recorded for 108 cases. Our classification of MR and abortion may not be exactly comparable to the terminologies used in other studies. ${ }^{30}$

The DSS records causes of death. The completeness of these records is very high, but maternal death may be underreported because of misclassification. The DSS defines a maternal death as "the death of a woman during pregnancy or within 42 days of pregnancy outcome from any cause related to or aggravated by the pregnancy or its management, but not from accidental or incidental causes." 31 Investigators collected further information to improve the identification of maternal deaths that occurred between 1976 and 2005 and their causes. ${ }^{23,26,32}$ As part of this effort, trained female interviewers collected data from relatives of all deceased women aged 15-49 under investigation, medical assistants conducted verbal autopsies with relatives of the deceased, and a team of physicians reviewed all of the information related to the cause of death. The investigators used an extended definition of maternal death-a death within 90 days of a pregnancy outcome ${ }^{33}$ and this is the definition we used in this study (including for deaths after 2005). We repeated our analyses for maternal deaths within 42 days; the main findings did not differ from those reported here.

We examined all pregnancies that occurred in Matlab in 1989-2008 (excluding 2001). We excluded from the analysis 1,073 pregnancies that resulted in multiple births (twins or triplets), because women with such outcomes may have different mortality risks. We also excluded 75 cases in which the woman died during pregnancy before having an outcome and 15 accidental deaths that occurred during pregnancy. We used the resulting sample, consisting of 121,464 pregnancy outcomes, to calculate the incidence of MR and abortion among women with singleton pregnancies.

The sample for our mortality analyses excluded 3,426 pregnancies that ended in stillbirth and 7,886 that ended in spontaneous miscarriage, because we examined the mortality associated with these outcomes in a previous study. ${ }^{12}$ The sample for the mortality analyses thus consisted of 110,152 singleton pregnancies-104,941 resulting in live births, 3,489 ending in MR and 1,722 ending in abortion. Using DSS identification numbers to match death records with records on pregnancy outcomes, we identified

\footnotetext{
*Since the intervals between interviews have become longer over time, such underreporting, if it exists, would lead to an overestimate of the extent of decrease in the incidence of termination or an underestimate of the extent of increase. As we show below, we found an increase in the incidence of termination; hence, the extent of that increase may be somewhat larger than reported here.
} 


\begin{tabular}{|c|c|c|c|c|c|c|c|c|}
\hline No. of pregnancy outcomes§ & 71,100 & 32,575 & 38,525 & na & 50,364 & 24,778 & 25,586 & na \\
\hline Pregnancy terminations per 100 pregnancy outcomes & 3.54 & 2.33 & 4.57 & $0.51^{* * *}$ & 5.35 & 3.85 & 6.79 & $0.57^{* * *}$ \\
\hline
\end{tabular}

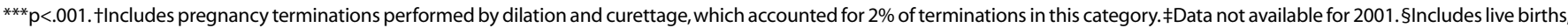

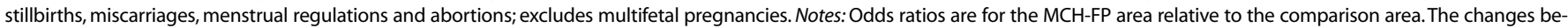

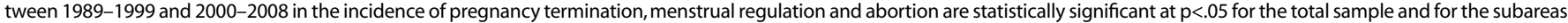

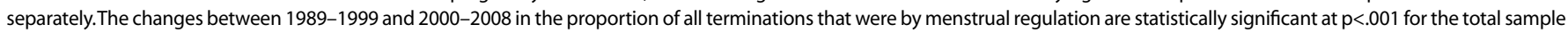
and for the subareas separately. Sum of menstrual regulations and abortions may not equal pregnancy terminations because of rounding. na=not applicable.

153 maternal deaths among these 110,152 pregnancies.*

We compared the mortality risks associated with MR and abortion with that associated with live birth, separately for the time periods 1989-1999 and 2000-2008 and separately for the two areas of Matlab. We calculated the maternal mortality risk, or case-fatality rate, for each outcome by dividing the number of deaths associated with that outcome by the number of such outcomes, and present these as risks per 100,000 outcomes. We note that some of the cell sizes are quite small for assessing casefatality rates; although the level of maternal mortality in Bangladesh is high compared with that in other countries, maternal death is still a relatively rare event. Appendix Table 1 (page 116) shows case-fatality rates and the numbers of deaths and cases for the subgroups we consider. For example, in the MCH-FP area, there were 329 abortions and seven deaths in 1989-1999, and 197 abortions and one death in 2000-2008

To compare risks by pregnancy outcome, time period and area, we calculated odds ratios. To assess whether the mortality risks associated with MR or abortion differ from that associated with live birth when demographic and socioeconomic characteristics are held constant, we estimated adjusted odds ratios using logistic regressions that adjusted for factors linked to maternal mortality in previous studies: maternal age, pregnancy order, interpregnancy interval, previous child deaths, previous pregnancy losses, maternal education, household space (a proxy for household wealth), religion and calendar year.

We also performed a simulation to understand the relative contributions of changes in the type of termination

\footnotetext{
*During the study period, there were 58,096 pregnancy outcomes in the comparison area and 52,056 in the MCH-FP area, yielding annual means of 3,058 and 2,740. On average, about 30,000 women aged 15-49 lived in each area.

tOur companion article ${ }^{6}$ reports trends by year in MR and abortion.

FIn the MCH-FP area, the date of a woman's last menstrual period was reported in about $90 \%$ of cases. However, in the comparison area, the date of last menstrual period was not available before 2001 and thus is available for only $46 \%$ of cases in $1989-2008$. We calculated the duration of pregnancy by subtracting the date of conception (estimated as the date of the last menstrual period plus two weeks) from the date of termination, and provide data for both time periods for the MCH-FP area and for the later period for the comparison area.
}

method and in method-specific case fatality to the overall case-fatality rate. In particular, we applied the methodspecific case-fatality rates for 2000-2008 to the distribution of termination methods in 1989-1999 and compared the resulting rate to the actual maternal mortality rates in both periods. We did this for Matlab as a whole and for each subarea.

In addition, to shed more light on trends in maternal mortality, we looked at changes in pregnancy duration prior to MR or abortion to see if termination services were sought at an earlier stage of pregnancy than in the past. We used data on the duration of pregnancy at the time of termination for cases in which the date of a woman's last menstrual period was reported. ${ }^{\ddagger}$ We also looked at the distributions of methods for abortions reported in the DSS to see if there had been a change in the proportion of women using each abortion method. We did this for each time period for Matlab as a whole; however, sample sizes were too small to permit us to look at differences between the two subareas. Similarly, our sample was not large enough for us to examine differences in case-fatality rates according to pregnancy duration or abortion method.

\section{RESULTS}

For Matlab as a whole, the proportion of pregnancies that were terminated (by either MR or abortion) increased from $3.5 \%$ in $1989-1999$ to $5.4 \%$ in $2000-2008$ (Table 1 ). Increases occurred in both subareas-from $2.3 \%$ to $3.9 \%$ in the MCH-FP area and from $4.6 \%$ to $6.8 \%$ in the comparison area. The incidence of MR increased as well, and to a greater extent than did overall termination: from 1.9\% to $4.2 \%$ for Matlab as a whole, from $1.3 \%$ to $3.1 \%$ in the $\mathrm{MCH}-\mathrm{FP}$ area and from $2.4 \%$ to $5.3 \%$ in the comparison area. The incidence of abortion, however, declined from $1.6 \%$ to $1.1 \%$ for Matlab as a whole, from $1.0 \%$ to $0.8 \%$ in the MCH-FP area and from $2.1 \%$ to $1.5 \%$ in the comparison area. In both time periods, the incidence of MR and of abortion was lower in the MCH-FP area than in the comparison area, as we had hypothesized (odds ratios, 0.50.6). For Matlab as a whole, the share of terminations done by MR increased from 55\% in 1989-1999 to 79\% in 20002008. This share also increased in both subareas. However, 
no difference was apparent between areas in either time period, so our hypothesis that the share of terminations that were done by MR would be greater in the MCH-FP area than in the comparison area was not supported.

In Matlab as a whole, the maternal mortality risk (or case-fatality rate) for abortion was larger than that for MR in both time periods (Figure 1; data and results of significance testing are shown in Appendix Table 1). In the $\mathrm{MCH}-\mathrm{FP}$ area, the difference was statistically significant for the earlier time period (2,128 vs. 233 per 100,000 procedures, respectively); although a similar pattern was evident in 2000-2008 (508 vs. 0 per 100,000), we could not test this difference statistically because of the zero value for MR. The differences between the case-fatality rates for the two methods were not statistically significant in the comparison area in either time period. Thus, our hypothesis that the maternal mortality risk associated with MR would be lower than that for abortion was supported for Matlab as a whole, but not for the comparison area.

Figure 1 and Appendix Table 1 also show moderate declines in the case-fatality rate for live births-by $14 \%$ in Matlab as a whole, $8 \%$ in the comparison area and $18 \%$ in the MCH-FP area-although none of these changes were statistically significant.

Much greater declines in case fatality were apparent for pregnancies that were terminated. In Matlab as a whole, the fatality rate from pregnancy termination fell from 953 per 100,000 in $1989-1999$ to 186 per 100,000 in 20002008 , an $81 \%$ decline (Appendix Table 1). The decline was greater in the MCH-FP area (90\%) than in the comparison area $(75 \%)$. Rates also decreased for each of the two categories of termination methods. For Matlab as a whole, case fatality from abortion fell by $65 \%$, from 1,480 per 100,000 to 524 per 100,000 . The decline in case fatality from MR was even greater-82\% (from 511 to 94 per 100,000).

The decrease in maternal mortality associated with abortion was $56 \%$ in the comparison area and $76 \%$ in the MCH-FP area. The difference between areas was not statistically significant, contrary to our hypothesis. The difference between areas was more pronounced for MR: Case fatality declined by $77 \%$ in the comparison area, but by even more in the MCH-FP area, where no deaths occurred among the 758 women who had an MR in 2000-2008. However, the lack of deaths precluded a statistical comparison.
FIGURE 1. Maternal mortality risk by type of pregnancy
outcome, according to time period, Matlab, Bangladesh, 1989-2008

1989-1999
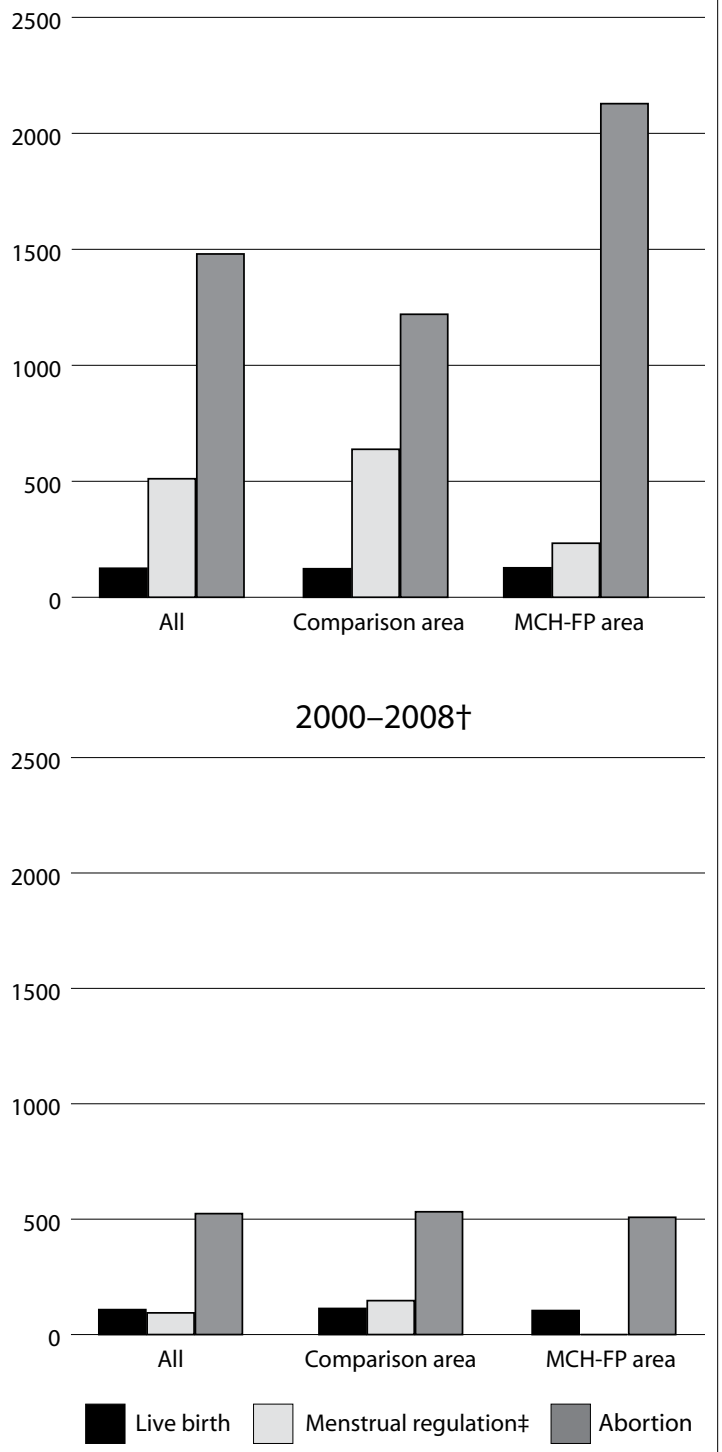

Note: Maternal mortality risk is measured as deaths per 100,000 outcomes. †Data not available for 2001 . IIncludes pregnancy terminations performed by dilation and curettage, which accounted for $2 \%$ of terminations in this category.

\begin{tabular}{|c|c|c|c|c|c|c|}
\hline \multirow[t]{2}{*}{ Comparison } & \multicolumn{3}{|c|}{ 1989-1999 } & \multicolumn{3}{|c|}{ 2000-2008t } \\
\hline & All & $\begin{array}{l}\text { Comparison } \\
\text { area }\end{array}$ & $\begin{array}{l}\mathrm{MCH}-\mathrm{FP} \\
\text { area }\end{array}$ & All & $\begin{array}{l}\text { Comparison } \\
\text { area }\end{array}$ & $\begin{array}{l}\text { MCH-FP } \\
\text { area }\end{array}$ \\
\hline All pregnancy terminations relative to live birth & $7.70^{* * *}$ & $7.45^{* * *}$ & $8.41^{* * *}$ & 1.71 & 2.04 & 1.01 \\
\hline Menstrual regulation $\ddagger$ relative to live birth & $4.11^{* * *}$ & $5.21^{* * *}$ & 1.84 & 0.87 & 1.30 & Undefined§ \\
\hline Abortion relative to live birth & $12.02^{* * *}$ & $10.02^{* * *}$ & $17.14^{* * *}$ & $4.85^{* *}$ & $4.74^{*}$ & 4.90 \\
\hline Menstrual regulation $\neq$ relative to induced abortion & $0.34^{*}$ & 0.52 & $0.11^{*}$ & $0.18^{*}$ & 0.27 & Undefined§ \\
\hline
\end{tabular}

${ }^{*} \mathrm{p}<.05 .{ }^{* *} \mathrm{p}<.01$. $^{* * *} \mathrm{p}<.001$. Data not available for 2001 . Includes pregnancy terminations performed by dilation and curettage, which accounted for $2 \%$ of

terminations in this category. §Odds ratio could not be calculated because no deaths occurred in the menstrual regulation group. 
TABLE 3. Observed case-fatality rates in 1989-2008, and simulated rates in 2000-2008 under scenario in which proportions of termination methods were those of 1989-1999, by area

\begin{tabular}{|c|c|c|c|c|c|c|c|}
\hline \multirow[t]{3}{*}{ Area } & \multicolumn{3}{|l|}{ Observed } & \multicolumn{2}{|l|}{ Simulated } & \multirow{3}{*}{$\begin{array}{l}\% \text { of decline } \\
\text { attributable to } \\
\text { changes in } \\
\text { method-specific } \\
\text { case-fatality rates }\end{array}$} & \multirow{3}{*}{$\begin{array}{l}\% \text { of decline } \\
\text { attributable } \\
\text { to change in } \\
\text { method usage }\end{array}$} \\
\hline & \multicolumn{2}{|c|}{$\begin{array}{l}\text { Case-fatality rate for all } \\
\text { pregnancy terminations }\end{array}$} & \multirow[t]{2}{*}{$\%$ decline } & \multirow{2}{*}{$\begin{array}{l}\text { Case-fatality rate } \\
\text { for all pregnancy } \\
\text { terminations, } \\
2000-2008\end{array}$} & \multirow[t]{2}{*}{$\%$ decline } & & \\
\hline & 1989-1999 & $2000-2008$ & & & & & \\
\hline All & 953 & 186 & 81 & 290 & 70 & 86 & 14 \\
\hline Comparison & 909 & 230 & 75 & 326 & 64 & 85 & 15 \\
\hline MCH-FP & 1,055 & 105 & 90 & 220 & 79 & 88 & 12 \\
\hline
\end{tabular}

In 1989-1999, the case-fatality rate from abortion was 1,220 per 100,000 in the comparison area and 2,128 per 100,000 in the MCH-FP area; the difference is not statistically significant, a finding contrary to our expectation that the rate would be lower in the MCH-FP area. The 20002008 case-fatality rates associated with abortion were similar in the comparison and MCH-FP areas (532 and 508 per 100,000 , respectively). The case-fatality rates from MR in the comparison and MCH-FP areas were 638 and 233 per 100,000, respectively, in 1989-1999, and 147 and 0 per 100,000 in 2000-2008; the former difference was not significant and the latter, again, could not be analyzed statistically. Nonetheless, these results support our hypothesis that mortality risks associated with MR and abortion have each declined. The hypothesis that the MCH-FP area had lower case-fatality rates than the comparison area was not supported, however.

Table 2 (page 113) shows these data in another wayas odds ratios comparing the mortality risks associated with MR, abortion or both relative to the risk associated with live births. A marked change in fatality risk occurred between 1989-1999 and 2000-2008, as values were substantially higher in the former period than in the latter. For the earlier period, all of the odds ratios for these comparisons are very large and highly statistically significant, with the exception of the comparison between MR and live birth in the MCH-FP area. For example, in the comparison area, the odds of death among women who had had an MR were 5.2 times those among women who had a live birth, and the odds among women who had had an abortion were 10.0 times those among women who had had a live birth. Similarly, in this earlier time period, women in the MCH-FP area who had had an abortion had 17.1 times the odds of dying relative to those who had had live births. In 2000-2008, overall termination and MR were no longer associated with elevated mortality risks in either subarea or in Matlab as a whole. However, mortality was higher for abortion than for live birth in the comparison area (odds ratio, 4.7) and in Matlab overall (4.9); the odds ratio for the MCH-FP area was similar in magnitude (4.9) but not statistically significant, most likely because of the small number of abortions in the area in that time period. Mortality risk from MR was significantly lower than that from abortion in both time periods (0.3 in 1989-1999 and 0.2 in 2000-2008) in Matlab as a whole.
We also estimated adjusted odds ratios for all of the cells in Table 2. These analyses adjusted for maternal age, gravidity, pregnancy interval, previous child deaths, previous pregnancy losses, maternal education, household space, religion and calendar year. Results (not shown) were similar to those in Table 2. For 1989-1999, nearly all of the associations that had been statistically significant in the unadjusted analyses remained so in the adjusted analyses $(p<.05)$, although the odds ratios were generally smaller; the exception was the comparison between MR and live births in the total sample, which was no longer significant. In contrast, none of the adjusted odds ratios for the later time period were statistically significant, meaning that in both areas the excess risk of dying from abortion or MR was no longer apparent.

To understand the relative contributions of two trendschange in the distribution of termination methods, and changes in method-specific case-fatality rates-to the overall case-fatality rate, we calculated what the rate would have been in 2000-2008 if the proportions of terminations done by MR and abortion had remained unchanged from 1989-1999 but the method-specific case-fatality rate had been that of 2000-2008. The results indicate that for Matlab as a whole, the case fatality from all terminations would have been 290 per 100,000 instead of the observed 186 per 100,000 (Table 3), meaning that the decline would have been $70 \%$ rather than the $81 \%$ that actually occurred. This suggests that most of the decline in the case-fatality rate $(86 \%$, or $70 / 81)$ is attributable to the decrease in method-specific mortality risks. The proportion of the decline due to changes in method-specific casefatality rates was similar in the two subareas-85\% for the comparison area and $88 \%$ for the MCH-FP area. Given that considerable changes in the proportion of terminations done by each method occurred during the study period, the proportion of the decline that was due to these changes was surprisingly small-15\% for the comparison area and $12 \%$ for the MCH-FP area. Hence, while our results support the hypothesis that the decline in the mortality risk from pregnancy termination was due both to reductions in the case-fatality rates for MR and abortion and to changes in the relative usage of these two methods, the former accounts for much more of the decline than the latter does.

Our final analyses examined whether improvements in care-seeking behavior may have contributed to the de- 
TABLE 4. Percentage distribution of terminated pregnancies, by duration at time of termination, and mean duration-all according to area, time period and type of termination

\begin{tabular}{|c|c|c|c|c|c|c|}
\hline \multirow[t]{3}{*}{ Pregnancy duration } & \multicolumn{4}{|l|}{ MCH-FP area } & \multirow{2}{*}{\multicolumn{2}{|c|}{$\begin{array}{l}\text { Comparison areat } \\
\text { 2000-2008‡ }\end{array}$}} \\
\hline & \multicolumn{2}{|l|}{ 1989-1999 } & \multicolumn{2}{|l|}{ 2000-2008‡ } & & \\
\hline & $\begin{array}{l}\text { Menstrual } \\
\text { regulation§ } \\
(\mathrm{N}=367)\end{array}$ & $\begin{array}{l}\text { Abortion } \\
(\mathrm{N}=272)+\dagger\end{array}$ & $\begin{array}{l}\text { Menstrual } \\
\text { regulation§ } \\
(\mathrm{N}=702) \neq \ddagger\end{array}$ & $\begin{array}{l}\text { Abortion } \\
(\mathrm{N}=181) \S \S, \dagger \neq\end{array}$ & $\begin{array}{l}\text { Menstrual } \\
\text { regulation§ } \\
(\mathrm{N}=1,250) \dagger ‡\end{array}$ & $\begin{array}{l}\text { Abortion } \\
(\mathrm{N}=325)\end{array}$ \\
\hline$<6$ wks. & 7.9 & 5.1 & 9.4 & 6.1 & 6.0 & 4.3 \\
\hline 6-7 wks. & 22.9 & 11.8 & 33.9 & 22.7 & 16.7 & 16.9 \\
\hline $8-9$ wks. & 25.1 & 18.0 & 25.2 & 23.8 & 31.1 & 29.5 \\
\hline 10-11 wks. & 16.3 & 19.5 & 14.4 & 12.7 & 17.0 & 17.5 \\
\hline$\geq 12$ wks. & 27.8 & 45.6 & 17.1 & 34.8 & 29.2 & 32.0 \\
\hline Total & 100.0 & 100.0 & 100.0 & 100.0 & 100.0 & 100.0 \\
\hline Mean duration (in wks.) & 7.8 & 8.7 & 7.0 & 7.4 & 8.3 & 9.0 \\
\hline
\end{tabular}

tData for 1989-1999 are unavailable for the comparison area because information on the date of women's last menstrual period was not collected until 2001. ‡Data not available for 2001. §Includes pregnancy terminations performed by dilation and curettage, which accounted for $2 \%$ of terminations in this category. ††Different from distribution for menstrual regulation in 1989-1999 at $p<.01$. \#‡Different from distribution for menstrual regulation in $1989-1999$ at $\mathrm{p}<.001$. $\S \mathrm{Different}$ from distribution for abortion in 1989-1999 at $\mathrm{p}<.01$. $† \neq$ Different from distribution for menstrual regulation in $\mathrm{MCH}-\mathrm{FP}$ area in 2000 2008 at $p<.01$. Note: Percentages may not total 100.0 because of rounding

clines in mortality from pregnancy termination. First, we assessed whether women sought to terminate pregnancies earlier in pregnancy than previously. In the MCH-FP area, the proportion of MRs and abortions that were performed at later gestational ages declined (Table 4). For example, in 1989-1999, 28\% of MRs were performed at 12 weeks or later, compared with $17 \%$ in $2000-2008$. (MR is not legally permitted after 10 weeks of pregnancy, but, as our data show, such procedures do occur.*) Similarly, 46\% of abortions were performed at 12 weeks or later in 19891999 , compared with $35 \%$ of those in $2000-2008$. These findings support the hypothesis that in recent years pregnancies were terminated earlier than in the past.

The data also show that, in both time periods and in both regions, MRs were performed earlier during pregnancy than abortions were, which may help explain why case-fatality rates were lower for the former than for the latter. For example, in the earlier time period, MRs were performed, on average, about a week earlier than abortions were ( 7.8 vs. 8.7 weeks). Moreover, a comparison of the two Matlab areas shows that in 2000-2008 (the only period for which we have data on both areas), 17\% of MRs were done at 12 weeks or later in the MCH-FP area, compared with $29 \%$ of those in the comparison area. This finding may help explain why case-fatality rates were lower in the MCH-FP area than in the comparison area. However, the proportions of abortions performed at 12 weeks or

\begin{tabular}{|c|c|c|}
\hline Method & $\begin{array}{l}1989-1999 \\
(\mathrm{~N}=1,149)\end{array}$ & $\begin{array}{l}2000-2008+ \\
(N=573)\end{array}$ \\
\hline $\begin{array}{l}\text { Use of drug (inserted, ingested } \\
\text { or injected) }\end{array}$ & 28.2 & 67.9 \\
\hline Internal manipulation of the genitalia & 63.6 & 15.7 \\
\hline Manipulation of the abdomen & 3.0 & 8.0 \\
\hline Other/unknown & 5.2 & 8.4 \\
\hline Total & 100.0 & 100.0 \\
\hline
\end{tabular}

later were similar in the two areas in 2000-2008.

There also appears to have been an improvement in the methods of abortion women use. In 1989-1999, 64\% of women who obtained an abortion had their termination through "internal manipulation of female genitalia"; this proportion fell to 16\% in 2000-2008 (Table 5). Conversely, the use of drugs (by insertion, ingestion or injection) increased from $28 \%$ to $68 \%$. These changes support our final hypothesis, that safer ways of termination have been used in recent years. Because internal manipulation of the female genitalia may be more likely than other approaches to lead to infection, women who have an abortion are probably less likely to become infected than they were in the past. We should note, however, that we do not know what drugs women used to terminate pregnancy. One may be misoprostol, which has been available over the counter in pharmacies in Bangladesh in recent years.

\section{DISCUSSION}

We analyzed high-quality longitudinal data on more than 110,000 pregnancies that ended in a live birth, MR or abortion over a period of 20 years in Matlab, Bangladesh. In 1989-1999, roughly half of terminations (55\%) were by MR (or, in a small proportion of cases, D\&C), and the rest were by presumably less-safe methods (illegal abortion). During the next decade (2000-2008), the proportion of terminations performed using safe methods increased to $79 \%$. This figure is much higher than that recently reported by Singh and colleagues, who analyzed data from a 2010 national survey and found that the incidence of MR and that of abortion were almost equal. ${ }^{4}$ However, that study was national and used an indirect estimation technique, which may account for the difference in findings.

The incidence of MR and abortion were significantly

*These later cases were disproportionately likely to be done by D\&C; for example, $11 \%$ of "MR" cases that were terminated at 12 weeks or later were by D\&C, compared with fewer than $2 \%$ of those terminated earlier in pregnancy. 
lower in the MCH-FP area than in the comparison area during both periods considered here, supporting our hypothesis that women in the former area are less likely than those in the comparison area to terminate their pregnancies.

We found no differences between the two areas in casefatality rates for live births, despite the superior maternal health services in the MCH-FP area. Previous research ${ }^{4}$ also found that the level of maternal mortality associated with live births was similar in the two areas of Matlab and attributed the lack of difference to the fact that the homes in both areas were, on average, equally accessible to the Chandpur District Hospital, which provides comprehensive emergency obstetric care. ${ }^{15,25}$

The case-fatality rate for MRs in Matlab as a whole in 1989-1999 was high-511 maternal deaths per 100,000. This is more than four times the rate associated with live birth, and more than twice the 220 per 100,000 mortality rate for unsafe terminations observed worldwide in 2008. ${ }^{27}$ We conjectured that the risk associated with MR would be similar to, or even lower than, that for live birth, since MR is supposed to be a relatively safe method; apparently, the method was not performed in a safe way in Matlab during the 1990s. It is encouraging that by 20002008, the case-fatality rate had declined remarkably, to a level quite close to that of live birth-a solid indication of improvement in safety, and a tremendous achievement in reproductive health care in Bangladesh.

We also found, as hypothesized, that the mortality risk associated with abortion was higher than that associated with MR. In 1989-1999, the case-fatality rate for abortion was 1,480 maternal deaths per 100,000 abortions, more than six times that from unsafe abortions worldwide ${ }^{27}$ and 12 times that for live birth in Matlab. The mortality risk for abortion declined dramatically, but in 2000-2008 it was still nearly five times that for live birth. This association was no longer apparent in the adjusted analysis, however, suggesting that the elevated mortality risk was largely at- tributable to the characteristics of women who seek such abortions.

In addition to the remarkable declines in the fatality rates for each type of termination, we found that MR accounted for an increasing proportion of terminations$79 \%$ in $2000-2008$ versus $55 \%$ in $1989-1999$. Our simulation showed that the vast majority ( $85 \%$ ) of the decrease in mortality associated with pregnancy termination was due to declines in method-specific case-fatality rates, rather than to the increased share of MR. Our analyses provide some suggestive evidence about the reasons for the declines in method-specific case-fatality rates: MR and abortion are now performed earlier in pregnancy than in the 1990s, and abortions are now done using less harmful methods than in the past (fewer are done by internal manipulation of the genitalia, and more by use of drugs).

The various findings just mentioned-the reductions in case-fatality rates, the increasing share of terminations done by MR, the growing use of safer methods of abortion and the earlier gestational age at time of termination-provide some clues to why maternal mortality continues to decline in Bangladesh in spite of the increase in the pregnancy termination rate. However, the case-fatality rate associated with MR in the comparison area in 2000-2008 was not as low as might be expected given that, if performed correctly, MR and D\&C should have lower case-fatality rates than live births have. The reasons for this should be investigated. An investigation of MR in the MCH-FP area, where there were no deaths associated with the procedure in the more recent period, might yield some useful lessons for the comparison area. Furthermore, despite considerable declines, we still find unacceptably high mortality among women who obtain abortions. Systematic evaluation should be done to find ways of reducing this risk. More information is also needed on why and under what conditions women seek abortion as an alternative to MRa topic addressed by the next article in this issue.

\begin{tabular}{|c|c|c|c|c|c|c|c|c|c|}
\hline \multirow{2}{*}{$\begin{array}{l}\text { Pregnancy } \\
\text { outcome }\end{array}$} & \multicolumn{3}{|l|}{ 1989-1999 } & \multicolumn{3}{|l|}{$2000-2008+$} & \multicolumn{3}{|c|}{$\%$ decline } \\
\hline & All & $\begin{array}{l}\text { Comparison } \\
\text { area }\end{array}$ & $\begin{array}{l}\mathrm{MCH}- \\
\text { FParea }\end{array}$ & All & $\begin{array}{l}\text { Comparison } \\
\text { area }\end{array}$ & $\begin{array}{l}\mathrm{MCH}- \\
\text { FP area }\end{array}$ & All & $\begin{array}{l}\text { Comparison } \\
\text { area }\end{array}$ & $\begin{array}{l}\mathrm{MCH}- \\
\mathrm{FP} \text { area }\end{array}$ \\
\hline Live birth & $\begin{array}{l}125 \\
(78 / 62,528)\end{array}$ & $\begin{array}{l}123 \\
(41 / 33,317)\end{array}$ & $\begin{array}{l}127 \\
(37 / 29,211)\end{array}$ & $\begin{array}{l}108 \\
(46 / 42,413)\end{array}$ & $\begin{array}{l}113 \\
(24 / 21,281)\end{array}$ & $\begin{array}{l}104 \\
(22 / 21,132)\end{array}$ & 14 & 8 & 18 \\
\hline $\begin{array}{l}\text { All pregnancy } \\
\text { terminations }\end{array}$ & $\begin{array}{l}953 \\
(24 / 2,518)\end{array}$ & $\begin{array}{l}909 \\
(16 / 1,760)\end{array}$ & $\begin{array}{l}1,055 \\
(8 / 758)\end{array}$ & $\begin{array}{l}186 \neq \\
(5 / 2,693)\end{array}$ & $\begin{array}{l}230 \S \\
(4 / 1,738)\end{array}$ & $\begin{array}{l}105+t \\
(1 / 955)\end{array}$ & 81 & 75 & 90 \\
\hline $\begin{array}{l}\text { Menstrual } \\
\text { regulationsłキ }\end{array}$ & $\begin{array}{l}511 \\
(7 / 1,369)\end{array}$ & $\begin{array}{l}638 \\
(6 / 940)\end{array}$ & $\begin{array}{l}233 \\
(1 / 429)\end{array}$ & $\begin{array}{l}94 \S \S \\
(2 / 2,120)\end{array}$ & $\begin{array}{l}147 \\
(2 / 1,362)\end{array}$ & $\begin{array}{l}0 \\
(0 / 758)\end{array}$ & 82 & 77 & 100 \\
\hline Abortion & $\begin{array}{l}1,480 \dagger \neq \\
(17 / 1,149)\end{array}$ & $\begin{array}{l}1,220 \\
(10 / 820)\end{array}$ & $\begin{array}{l}2,128+\S \\
(7 / 329)\end{array}$ & $\begin{array}{l}524 \neq \S \\
(3 / 573)\end{array}$ & $\begin{array}{l}532 \\
(2 / 376)\end{array}$ & $\begin{array}{l}508 \\
(1 / 197)\end{array}$ & 65 & 56 & 76 \\
\hline
\end{tabular}

tData not available for 2001. $\neq$ Different from value for all pregnancy terminations in 1989-1999 at $\mathrm{p}<.05$. §Different from value for all pregnancy terminations in comparison area in 1989-1999 at $\mathrm{p}<.05$. †+Different from value for all pregnancy terminations in MCH-FP area in 1989-1999 at $\mathrm{p}<.05$. $\neq \neq$ Includes pregnancy terminations performed by dilation and curettage, which accounted for $2 \%$ of terminations in this category. $\S$ Different from value for menstrual regulations in comparison area in 1989-1999 at $p<.05$. $† \neq D$ Different from value for menstrual regulations in comparison area in 1989-1999 at $p<.05$. $\uparrow \S D$ ifferent from value for menstrual regulations in MCH-FP area in 1989-1999 at $p<.05$. ₹§Different from value for menstrual regulations in both areas in $2000-2008$ at $p<.05$. Note: Case-fatality rates are per 100,000 cases. 


\section{REFERENCES}

1. World Health Organization (WHO) et al., Trends in Maternal Mortality: 1990 to 2008, Geneva: WHO, 2010.

2. National Institute of Population Research and Training (NIPORT), MEASURE Evaluation and International Centre for Diarrhoeal Disease Research, Bangladesh (ICDDR,B), Bangladesh Maternal Mortality and Health Care Survey 2010, Dhaka, Bangladesh: NIPORT; and Chapel Hill, NC, USA: MEASURE Evaluation, 2012.

3. NIPORT, ORC Macro and ICDDR,B, Bangladesh Maternal Health Services and Maternal Morbidity Survey 2001, Dhaka, Bangladesh: NIPORT; and Calverton, MD, USA: ORC Macro, 2003.

4. Singh $S$ et al., The incidence of menstrual regulation procedures and abortion in Bangladesh, 2010, International Perspectives on Sexual and Reproductive Health, 2012, 38(3):122-132.

5. Singh S et al., Estimating the level of abortion in the Philippines and Bangladesh, International Family Planning Perspectives, 1997, 23(3): 100-107 \& 144

6. DaVanzo J and Rahman M, Pregnancy termination in Matlab, Bangladesh: trends and correlates of use of safer and less-safe methods, International Perspectives on Sexual and Reproductive Health, 2014 40(3):119-126.

7. DaVanzo J, Rahman M and Ahmed S, Influences on pregnancytermination decisions in Matlab, Bangladesh, Demography, 2013, 50(5):1739-1764.

8. Ahmed K, Sarkar AH and Rahman M, Determinants of induced abortion in rural Bangladesh, Demography India, 1996, 25(1):105-118.

9. Rahman M, DaVanzo J and Razzaque A, Do better family planning services reduce abortion in Bangladesh? Lancet, 2001 , 358(9287):1051-1056

10. Streatfield PK, Role of abortion in fertility control, Journal of Health, Population, and Nutrition, 2001, 19(4):265-267.

11. Huda FA et al., Strengthening health system capacity to monitor and evaluate programmes targeted at reducing abortion-related maternal mortality, Reproductive Health Programme Working Paper, Dhaka, Bangladesh: ICDDR,B, 2010, No. 1.

12. Rahman M, DaVanzo J and Razzaque A, The role of pregnancy outcomes in the maternal mortality rates of two areas in Matlab, Bangladesh, International Perspectives on Sexual and Reproductive Health, 2010, 36(4):170-177

13. Chowdhury ME et al., Determinants of reduction in maternal mortality in Matlab, Bangladesh: a 30-year cohort study, Lancet, 2007, 370(9595):1320-1328

14. Chowdhury ME et al., Causes of maternal mortality decline in Matlab, Bangladesh, Journal of Health, Population, and Nutrition, 2009, 27(2):108-123.

15. Maine D et al., Why did maternal mortality decline in Matlab? Studies in Family Planning, 1996, 27(4):179-187.

16. Alauddin M, Maternal mortality in rural Bangladesh: the Tangail District, Studies in Family Planning, 1986, 17(1):13-21.

17. Khan AR, Jahan FA and Begum SF, Maternal mortality in rural Bangladesh: the Jamalpur District, Studies in Family Planning, 1986, 17(1):7-12.

18. Koenig MA et al., Maternal mortality in Matlab, Bangladesh: 197685, Studies in Family Planning, 1988, 19(2):69-80.

19. D'Souza S, A population laboratory for studying disease processes and mortality-the Demographic Surveillance System, Matlab, Bangladesh, Special Publication, Dhaka, Bangladesh: ICDDR,B, 1981, No. 13

20. Fauveau V, Matlab: Women, Children, and Health, Dhaka, Bangladesh: ICDDR,B, 1992.

21. Van Ginneken J et al., Health and demographic surveillance in Matlab: past, present, and future, Special Publication, Dhaka, Bangladesh: ICDDR,B, 1998, No. 72.

22. ICDDR,B, Health and Demographic Surveillance System, Matlab: Registration of Health and Demographic Events (1983-2005), Dhaka, Bangladesh: ICDDR,B, 2006.
23. NIPORT, Mitra Associates and ORC Macro, Bangladesh Demographic and Health Survey 2011, Dhaka, Bangladesh: NIPORT and Mitra and Associates; and Calverton, MD, USA: ORC Macro, 2013.

24. ICDDR,B, Health and Demographic Surveillance System-Matlab: Registration of health and demographic events 2008, Scientific Report, Dhaka, Bangladesh: ICDDR,B, 2010, No. 109

25. Ronsmans $C$ et al., Decline in maternal mortality in Matlab, Bangladesh: a cautionary tale, Lancet, 1997, 350(9094):1810-1814.

26. Fauveau V et al., Effect on mortality of community-based maternitycare programme in rural Bangladesh, Lancet, 1991, 338(8776):11831186.

27. Åhman E and Shah IH, New estimates and trends regarding unsafe abortion mortality, International Journal of Gynecology \& Obstetrics, 2011, 115(2):121-126.

28. Bartlett LA et al., Risk factors for legal induced abortion-related mortality in the United States, Obstetrics \& Gynecology, 2004, 103(4):729-737.

29. Lawson HW et al., Abortion mortality, United States, 1972 through 1987, American Journal of Obstetrics \& Gynecology, 1994, 171(5):13651372.

30. Vlassoff $\mathrm{M}$ et al., Menstrual Regulation and Postabortion Care in Bangladesh: Factors Associated with Access to and Quality of Services, New York: Guttmacher Institute, 2012.

31. WHO, International Statistical Classification of Diseases and Related Health Problems, 10th revision, Geneva: WHO, 1992.

32. Dieltiens $G$ et al., Met Need for Life-Saving Obstetric Surgery in Bangladesh: The Matlab-ICDDR,B Cohort-Study of Maternal Mortality 1990-2001 and the Results for a New Indicator to Assess Met Need for LifeSaving Obstetric Surgery, Dhaka, Bangladesh: ICDDR,B, 2005.

33. American Medical Association (AMA) Committee on Maternal and Child Care, A Guide for Maternal Death Studies, Chicago, IL, USA: AMA, 1964.

\section{RESUMEN}

Contexto: En Bangladesh, tanto la regulación menstrual (RM), método que se considera relativamente seguro, como el aborto, que supuestamente es un método menos seguro, se usan para la terminación del embarazo (confirmado o presuntivo). Sin embargo, se sabe poco sobre los cambios en el uso de estos métodos a través del tiempo o de la comparación de sus respectivos riesgos de mortalidad.

Métodos: Se usaron datos del Sistema de Vigilancia Demográfica de Matlab (Bangladesh) acerca de 110,152 resultados de embarazos ocurridos entre 1989 y 2008 para analizar los cambios en los riesgos de mortalidad asociados con la RM (así como con un número pequeño de procedimientos de dilatación y legrado), el aborto y el embarazo llevado a término. Se usaron análisis de tabulación y regresión logística para comparar los resultados en dos zonas de Matlab-la zona de comparación, la cual recibe servicios estándar de salud y planificación familiar del gobierno; y la zona de Salud Materna e InfantilPlanificación Familiar (SMI-PF), la cual recibe mejores servicios de salud y planificación familiar.

Resultados: En todo Matlab, la proporción de embarazos que terminaron en RM aumentó de 1.9\% en 1989-1999 a $4.2 \%$ en 2000-2008, mientras que la proporción de los que terminaron en aborto disminuyó de 1.6\% a 1.1\%. Las probabilidades de mortalidad relacionadas con la RM fueron 4.1 veces mayores que las relativas a los embarazos llevados a término en el período 1989-1999, pero dejaron de ser elevadas en 2000-2008. Por su parte, las probabilidades de mortalidad 
relacionadas al aborto fueron 12.0 y 4.9 veces mayores que las relativas a los embarazos llevados a término en 1989-1999 y 2000-2008, respectivamente. La reducción en el riesgo de mortalidad fue mayor en la zona SMI-PF que en la zona de comparación ( $90 \%$ vs. $75 \%$ ).

Conclusión: La RM ha dejado de exponer a las mujeres a un riesgo de mortalidad elevado en relación con los embarazos llevados a término; pero el aborto todavía lo hace.

\section{RÉSUMÉ}

Contexte: La régulation menstruelle (RM), considérée comme une méthode relativement sûre, et l'avortement, méthode vraisemblablement moins dénuée de risque, se pratiquent tous deux au Bangladesh pour interrompre la grossesse (connue ou soupçonnée). L'évolution dans le temps du recours à ces méthodes et les risques de mortalité comparés ne sont cependant guère documentés.

Méthodes: Les données du Système de surveillance démographique de Matlab (Bangladesh) concernant 110152 issues de grossesse entre 1989 et 2008, ont servi à évaluer l'évolution des risques de mortalité associés à la RM (ainsi qu'à un petit nombre de procédures de dilatation et curetage), à l'avortement et à la naissance vivante. Les issues ont été comparées par disposition en tableaux et analyses de régression logistique dans deux zones de Matlab: la zone de comparaison, qui bénéficie de services de santé et de planification familiale publics standard, et la zone Santé maternelle et de l'enfant-Planifi- cation familiale (SME-PF), bénéficiaire de meilleurs services. Résultats: Sur l'ensemble de Matlab, la proportion des grossesses interrompues par RM passe de 1,9\% en 1989-1999 à 4,2\% en 2000-2008, tandis que celle des grossesses interrompues par avortement diminue, de 1,6\% à 1,1\%. Le risque de mortalité associé à la RM représente 4,1 fois celui de la naissance vivante en 1989-1999, mais il n'est plus élevé en 2000-2008. Celui de l'avortement représente, respectivement, 12,0 et 4,9 fois celui de la naissance vivante en 1989-1999 et en 2000-2008. La réduction du risque de mortalité est supérieure dans la zone SME-PF (90\% par rapport à $75 \%$ dans la zone de comparaison).

Conclusion: La RM n'expose plus les femmes à un risque de mortalité élevé par rapport à celui de la naissance vivante; l'avortement, si.

\section{Acknowledgments}

Support was provided by the World Health Organization Research Program on Sexual and Reproductive Health, Geneva, through a grant to the International Centre for Diarrheal Disease Research, Bangladesh, which subcontracted services from Pathfinder International, where Dr. Rahman was employed when this research began. The authors thank Shahabuddin Ahmed for his assistance with the data analysis. The views expressed in this article are those of the authors and do not reflect the opinions of current or past employers or funders.

Author contact: rahmanm@email.unc.edu 